УДК [78.071.1:784.3]:781.68(44)«18»

Татьяна Васильевна Жарких

кандидат искусствоведения, доцент

Харковского национального университета искусств

имени И. П. Котляревского

num.kharkiv@i.ua

\title{
ИНТЕРПРЕТАТОР ВОКАЛЬНОГО ЦИКЛА «ПОЭМА ОДНОГО ДНЯ» Г. ФОРЕ В ПОИСКАХ ФРАНЦУЗСКОГО ШАРМА
}

Цель исследования - обосновать способы постижения глубинного смысла творения гения путем обнаружения релевантной ему модели исполнительской интерпретации. Научная новизна. В работе исследуется наименее изученное произведение в вокальном наследии франиузского композитора конца ХІХ - начала ХХ века Г. Форе. Методология работы опирается на аналитический, текстологический и лингвистический подходы, позволяющие затронуть интерпретационный аспект осмысления сложной музыкально-поэтической конструкции вокального иикла. Выводы. Шарм вокальной музыки Г. Форе заключается в соответствии музыкальных интонаций тончайшим нюансам фонетического строя поэтического языка. Композитор является изящным интерпретатором франиузской лирической поэзии, отвечающей его вкусам. Вокалисты, включающие в свой репертуар «Поэму одного дня» и исполняющие это произведение на языке перевода, лишают слушателя музыки поэтического текста, в результате чего теряется шарм фореевского искусства. Изучение франиузского языка - важнейшее звено в постижении тайны гения.

Ключевые слова: шарм, интерпретация, поэма, фонемы, mélodie.

Zharkikh Tatyana. Doctor of Philosophy, Associate professor of I. P. Kotlyarevsky Kharkiv National University of Arts

The interpreter of the vocal cycle «Poem of the day» by G. Faurŭ in search of french charm

Research objective - to justify methods of comprehension of a depth sense of creation of the genius by detection relevant to it model of performing interpretation. Scientific novelty. In operation the least studied work in vocal heritage of the French composer of the end of XIX - the beginnings of the XX century of $G$. Fauré is researched. The methodology of article relies on the analytical, textual and linguistic approaches allowing to affect interpretative aspect of judgment of difficult musical and poetic construction of a vocal cycle. Conclusion. The charm of vocal music of $G$. Fauré consists in compliance of musical intonations to the thinnest nuances of a phonetic system of poetic diction. The composer is the refined interpreter of the French lyrical poetry responding to its tastes. The

(C) Жарких Т. В., 2017 
vocalists including "The poem of one day» in the repertoire and executing this work in target language deprive of the listener of music of the poetic text therefore the charm of Faure's art is lost. French study - the major link in comprehension of a secret of the genius.

Keywords: charm, interpretation, poem, phonemes, mélodie.

Жаркіх Тетяна Василівна, кандидат мистецтвознавства, доцент Харківського національного університету мистецтв імені І. П. Котляревського

Інтерпретатор вокального циклу «Поема одного дня» Г. Форе у пошуках французького шарму

Мета дослідження - обгрунтувати способи осягнення глибинного сенсу творіння генія шляхом виявлення релевантної йому моделі виконавської інтерпретаціі. Наукова новизна. В роботі досліджується найменш вивчений твір у вокальный спадщині франиузького композитора кіния ХІХ - початку XX століття Г. Форе. Методологія роботи спирається на аналітичний, текстологічний та лінгвістичний підходи, що дозволяють торкнутися інтерпретаційного аспекту осмислення складної музично-поетичної конструкцї вокального циклу. Висновки. Шарм вокальної музики Г. Форе укладається відповідно музичним інтонаціям найтонших нюансів фонетичного ладу поетичної мови. Композитор $є$ витонченим інтерпретатором франиузької ліричної поезії, яка відповідає його смакам. Вокалісти, що включають в свій репертуар «Поему одного дня» і виконують ией твір на мові перекладу, позбавляють слухача музики поетичного тексту, в результаті чого втрачається шарм мистецтва Форе. Вивчення французької мови - найважливіша ланка в осягненні таємниці генія.

Ключові слова: шарм, інтерпретація, поема, фонеми, те́lodie.

Актуальность работы. Несмотря на то, что во Франции творчеству Г. Форе посвящено множество исследований, в отечественной музыкальной науке содержание целого ряда, в частности вокальных сочинений композитора остаётся загадкой. Утончённый и изысканный авторский текст теряется при приблизительном или вовсе неверном переводе. Для отечественных певцов фактически не ведомы традиции исполнения вокальной лирики Г. Форе. Более того, его многие вокальные циклы до настоящего времени звучат фрагментарно, а некоторые считаются «репертуарной редкостью».

Раскрытие сущности исполнительской драматургии вокальных сочинений французского композитора представляется актуальной задачей современного музыковедения, поскольку это позволит интерпретатору проникнуть в глубины авторского замысла, поможет разгадать французский шарм, свойственный сочинениям Г. Форе. 
Цель исследования - обосновать способы постижения глубинного смысла творения гения путем обнаружения релевантной ему модели исполнительской интерпретации.

Объект исследования - вокальное творчество Г. Форе.

Предмет исследования - исполнительская интерпретация, релевантная художественному содержанию вокального цикла Г. Форе «Поэма одного дня» на стихи Ш. Гранмужена (1880).

Научная новизна. В работе исследуется наименее изученное произведение в вокальном наследии французского композитора конца XIX - начала XX века Г. Форе.

Франция - одна из немногих стран мира, где музыка является частью образа жизни. Такой яркий представитель французской культуры, как П. Верлен начинает свой манифест «Поэтическое искусство» призывом: «Музыки, прежде всего» («De la musique avant toute chose»). Это объясняется музыкальной природой французского языка: в потоке речи трудно различить, где заканчивается одно слово и начинается следующее. Кроме того, фонетическая система французского языка включает 15 гласных, 17 согласных и 3 полугласных, всего 35 фонем, в русском языке -5 гласных, 1 полугласный и 36 согласных звуков, всего 42 фонемы. Таким образом, в русском языке преобладают согласные звуки, а во французском - гласные, что свидетельствует о большей мелодичности французского языка. Французский язык, а точнее фонемы французского языка настраивают на пение - томное, обворожительное, глубокое. Живая французская речь привносит в вокальную музыку изящество фразировки, интонационное богатство и неподдельное очарование - всё это определяется таким понятием, как «французский шарм».

О вокальной музыке Г. Форе также можно сказать, что ей свойственен французский шарм, но шарм особый, В. Янкелевич определяет его как «фореевский шарм» («уникальное обаяние» или «нечто невыразимое») [9].

Французские форееведы разделяют творчество композитора, исходя из стилевых и эстетических модификаций. Если придерживаться концепции Carol Kimball [10], наследие Г. Форе делится на 3 периода:

Ранний период творчества (1860-1865) характеризуется очаровательной сентиментальностью, свойственной французской народной песне, интенсивным использованием образцов предваряющей символизм парнасской поэзии как доминирующего направления в со- 
временной композитору французской литературе (парнасцы стремились к восстановлению правильного поэтического языка и отвергали чрезмерный лиризм романтиков, противопоставляя им устремлённость к отвлечённому).

В центральный период творчества (1880-1904) композитор продолжает использовать сочинения парнасских поэтов, хотя, вместе с тем, начинает проявляться его интерес к поискам поэтов-символистов, в частности к П. Верлена. Музыкальный язык Г. Форе в этот период, согласно Carol Kimball, характеризуется введением «утончённых гармоний, модальности, повышенной эмоциональности» [10,185].

В концепции Carol Kimball ранний и центральный периоды композитора разделены между собой весьма продолжительной «паузой», охватившей около 15 лет. Однако за этот период времени композитор создал целый ряд вокальных произведений, таких, например, как «Корабли» (Т. Готье), 1871; «Так как здесь внизу» (В. Гюго), дуэт для двух сопрано, 1874; «Джины» (В. Гюго), 4-гол. для смешанного хора с сопровождением оркестра или фортепиано, 1875, ор. 13. Поскольку вокальные сочинения сыграли значительную роль в творческой эволюции Г. Форе, а подтверждение этому можно найти, познакомившись с исследованиями Ж.-М. Некту, М. К. Бельтрандо-Патье [8; 11] и целого ряда других музыковедов, трудно объяснить, почему в предложенной периодизации остались исключёнными долгие годы работы французского Мастера.

Поздний период творчества Г. Форе (1906-1922) отделяет от предыдущего двухлетний интервал. Его возникновение обусловлено, возможно, как некий переходный этап в творчестве Г. Форе (в течение этого времени созданы: квинтет d-moll для ф-п и струнных, 1891-1905, седьмая баркарола для ф-п, 1905, четвертый экспромт для ф-п, 1905). В вокальных сочинениях этого периода композитор попрежнему опирается на эстетику символизма; музыкальному языку свойственны усложненные гармонии, усиливается интроспективность и, вместе с тем, сохраняется тот же шарм, что типичен для произведений раннего периода.

«Poème d'un jour (Поэма одного дня)» (1880) относится ко второму (центральному) периоду творчества Г. Форе. Существует научная гипотеза [3, 159], что данный вокальный цикл композитора стал своего рода эмоциональным выплеском после неудачной попытки построить любовные отношения с Марианной Виардо (дочерью знаменитой французской певицы Полины Виардо). Как отмечает С. Сигитов, 
«Разрыв поверг Форе в состояние полного оцепенения. Душевные страдания вызывают сильное нервное расстройство: его мучают приступы острой боли в голове и ушах - предвестники будущей страшной болезни. Отзвуки смятенного чувства слышны и в Первом фортепианном квартете (1879), и в вокальном триптихе «Поэма одного дня» $(1880)$, и в Элегии для виолончели и фортепиано $(1883) »[2,56]$.

Вокальный цикл «Поэма одного дня» (ор. 18), оформленный в виде своеобразных монологов, «мелодий», включает в себя три этапа развития внутренней драмы лирического героя: «Rencontre» («Встреча»), «Toujours» («Всегда») и «Adieu» («Прощание»). Каждая из перечисленных частей является, с одной стороны, самостоятельным произведением, а с другой, все три «мелодии» объединены общим тематизмом. Данный вокальный цикл является отдалённым прообразом более зрелого вокального цикла «Добрая песня».

B «Poème d'un jour» отразилась переходность интересов композитора, ознаменованная перемещением внимания от парнасской поэтики к семантике символизма. Не случаен и выбор поэтического первоисточника, принадлежащего парнасскому поэту и драматургу Шарлю Гранмужену (1850-1930), стилю которого присуща высокая степень символических обобщений. Музыкальность поэтического языка парнасского поэта была столь значительна, что он стал автором либретто ряда опер (например, С. Франка «Гульда», Мари де Гранваль «Мазепа», оратории Ж. Массне «Богородица»).

Все части вокального цикла связаны между собой монологом поэтического героя. Предполагаемый исполнитель - универсальный баритон, который может петь и более драматический репертуар, но при этом обладающий мягкостью голоса, способного передать тонкие полутона «мастера очарований» (выражение К. Дебюсси).

В первой «мелодии» «Rencontre» («Встреча») автор (он же и лирический герой) повествует о том, что в его жизни появилась прекрасная незнакомка, с которой связаны определённые перемены. До свидания с ней он был грустным, потерянным человеком. И вдруг происходит чудо: возникает «une mystèrieuse et douce sympathie (таинственная и нежная симпатия)», которая может перерасти в нечто большее. Лирического героя и молодую женщину многое объединяет, например, «ta tristesse sauvage a la mienne pareille (твоя дикая печаль на мою похожа)», они любят «а voir le soleil décliner sur la mer (видеть солнце, склонённое над морем)», «le charme des soirs (очарование вечеров)» дорого их родственным душам. Рассказчик открыто призна- 
ётся в любви к женщине, которую только встретил, и всё же сомнение не покидает его на протяжении всего первого номера: «Serais tu donc l'amie, qui rendrait le bonheur au poète isolé (была бы ты мне подругой, которая вернула бы счастье одинокому поэту?)».

Несколько неожиданна излишняя патетика поэтического текста: ведь лирический герой видит незнакомку впервые, и остаётся неясным, является ли чувство любви, возникшее у него, взаимным. Такое настроение - соединение меланхолии с атмосферой радости и восторга - типично для Г. Форе.

В первом монологе фортепианный аккомпанемент имеет особую фактурную прозрачность и приглушённость звучания. Лишь дважды это диафоническое сопровождение нарушено: в середине, на словах «Comme le ciel natal» (Как небо родное) и в финале. Однако в средней части «Встречи» - это лишь небольшой всплеск на $\boldsymbol{m f}$, отражающий восторг от сознания близости родственных душ, а в финале - это уже полноценное, мощное $\boldsymbol{f}$, заканчивающееся трёхтактовым тоническим утверждением. В традициях французского фольклора Г. Форе в этом номере сохраняет песенную строфичность. Композитор настолько тонко подбирает палитру ладовых оттенков, что от этого усиливается эвфония поэтического текста. В первом монологе автор использует одну из своих творческих находок - chant parlé (разговорное пение, декламация). Поскольку силлабическое стихосложение во французском языке определяет особенность музыкальной декламации, во «Встрече» мелодия подчиняется различным по величине ритмическим группам поэтического текста, объединяющим слова в единое звуковое целое.

Первая «Встреча» сменяется бурным вторым номером «Toujours» (Всегда), на что указывает выбор темпа - Allegro con fuoco. Как утверждает Gartside [5, 88], это, может быть, одна из самых драматических песен, написанных Г. Форе. Исполнителю данного произведения предоставляется возможность интерпретировать уход возлюбленной. Так становится понятным эмотивный характер «мелодии», по сути это отчаянный призыв, попытка убедить возлюбленную не покидать его. В этом номере явно проступают и гнев, и отчаяние: «n'espérez pas que non âme s'arrache à ses âpres douleurs (не надейтесь, что моя душа вырвется из пронзительной боли)».

Кроме того, название «Всегда» выбрано, очевидно, в связи с тем, что если бы чувства героя были бы взаимными, его любовь могла бы длиться вечно, всегда. 
В первом и втором номерах вокального цикла уже проступают те элементы, которые отражают музыкальную эстетику французского композитора. Это развитие движения в фортепианной партии: если в «Rencontre» оно ещё робкое и неустойчивое благодаря хроматизмам, то в «Toujours» - передающее душевное волнение и порыв. Во втором монологе Г. Форе использует триольность, которую R. Gartside называет «сексуальной», привносящей в музыку Г. Форе элемент чувственности [5]. Кроме того, триольный аккомпанемент эквивалентен шести восьмым, а вокальная партия написана четвертными длительностями. Возникает полиритмия, что усиливает неустойчивость и смятение этого номера. Таким образом, хрупкость первой «мелодии» достигается с помощью хроматизмов, а смятение и зыбкость второй - полиритмией. Диссонансы в фортепианной и вокальной партиях создают настроение отчаяния, как будто рассказчик пытается изменить происходящее, заставить свою возлюбленную понять его и принять правильное решение. Однако в конце второго номера фортепианная фактура становится иной, а финальный аккорд в F-moll на фермате создаёт ощущение, что решение принято - любовные отношения приходят к концу. Это подтверждают и динамические оттенки. В первом монологе есть надежда на продолжение знакомства, поэтому в финале этого номера указано $f$; а во втором - любовный порыв исчезает, поэтому логичным становится финальное $\boldsymbol{p}$. Такое лаконичное окончание «Toujours» является идеальным переходом и, возможно, предзнаменованием финального третьего номера «Adieu».

После моторики первых двух «мелодий» устойчивые четверти вступления воспринимаются как погребальный хорал - это похороны любви. Главный герой прощается со своей возлюбленной, а, как известно, прощание - это маленькая смерть. Однако третий монолог звучит в F-Dur и, в отличие от темпа второго номера (Allegro con fuoco), написан в Moderato, что воспринимается как успокоение между героями, их пути разошлись. Этот номер имеет трёхчастную репризную форму, и в финале композитор также использует аккордовый аккомпанемент, но хоральность исчезает, следовательно, не всё так трагично. Простота и спокойствие третьего номера отражает идею о том, что расставание является неотъемлемой частью жизни, в конце концов, это неизбежно, как изменяются «les flots des grèves (волны песчаных берегов)» или «la rose Déclose (распустившаяся роза)». И даже сам герой утверждает, что он покидает «vos charmes sans larmes (ваши чары без слёз)». 
Кроме того, само название «Adieu», в переводе означает окончательное прощание, т. е. вы никогда не увидите этого человека снова, в отличие от au revoir, которое предполагает прощание до новой встречи. Поэтому использование автором слова Adieu является намёком на то, что нет никаких шансов на примирение.

Настроение третьего монолога кардинально отличается от двух предыдущих. Возможно, Г. Форе подчёркивает, что даже самая возвышенная любовь, страсть в реальности непостоянны и имеют своё начало и конец. В финале вокального цикла звучит $\mathrm{F}^{2}$ (на слове Adieu), в динамике $p p$, что свидетельствует о неизбежном и окончательном прощании.

При исследовании данного вокального цикла возникает вопрос: почему Г. Форе избрал название «Поэма одного дня»? Lauren Cornwell объясняет это несколько ироническим подходом автора к данному вокальному циклу [13]. Г. Форе никогда не выбирал юмористические тексты для своих произведений, но уже в первом номере рассказчик с чрезмерным пафосом выражает свою страсть и любовь к женщине, которую только встретил. На протяжении второго номера герой слишком патетично объясняет, почему он не может выполнить её просьбу - просто уйти. И, наконец, по истечении слишком короткого времени (всего одного дня, как указано в названии вокального цикла) наш герой окончательно охладевает к предмету своей любви и успокаивается. Ирония заключается в том, что бурное и страстное признание в любви заканчивается полным равнодушием рассказчика. Трудно поверить в такую мимолётную любовь. Очевидно, что Г. Форе не воспринимал любовь с первого взгляда и относился к этому с насмешкой.

Однако существует и иная версия: «Поэма одного дня» была создана как протест против музыки Ж. Массне [6, 118]. Г. Форе не был поклонником этого композитора и воспринимал его произведения как слишком слащавые. Возможно, «Поэма одного дня» написана как пародия на такие сочинения Ж. Массне, как: «Октябрьская поэма», «Апрельская поэма», «Зимняя поэма». Но не все музыковеды придерживаются такого мнения, потому что, даже если Г. Форе и не был в восторге от творчества Ж. Массне, он не мог отрицать популярность этого композитора и, таким образом, не стал бы иронизировать по этому поводу.

Можно также предположить, что содержание вокального цикла отражает три стадии взросления человека: юность, которой свой- 
ственна импульсивность, восторженность; молодость - уязвимость, максимализм; зрелость - успокоение и примирение. Стадия старения не представлена, потому что в период написания этого произведения Г. Форе было только 35 лет, и что такое старость он ещё не знал. А название «Поэма одного дня» подразумевает «Поэму одной жизни».

Сейчас сложно понять истинные причины написания данного вокального цикла, но, очевидно, что исполнитель должен суметь разгадать загадку гения сам, исходя из музыкально-вербального текста. В этом и заключается тайна и очарование «Поэмы одного дня».

Подсказка интерпретации данного цикла кроется в том, что он написан в жанре mélodie, в основе которого взаимосвязь вербально-музыкального текста с грамматикой и фонетикой французского языка. Как отмечает музыковед М. Фор, «французская mélodie - это прославление поэзии через музыку» [4, 351]. Поэтому, чтобы проникнуть в глубины многомерного музыкально-поэтического материала произведения Г. Форе, необходимо провести анализ первоисточника Ш. Гранмужена (анализ ритмический, фонетический, синтаксический и т. д.).

Для французской поэзии характерно силлабическое стихосложение, в котором размер стиха определяется количеством слогов в стихотворной строке, а число ударений и их расположение не учитывается. Такой тип стихосложения характерен для языков с фиксированным ударением. Во французском языке оно на последнем слоге. Например, в первой «мелодии» «Rencontre» каждая строка состоит из 7 слогов, таким образом, силлабический размер соответствует семисложнику. В связи с тем, что все слоги обладают относительным акустическим равенством, возникает эстетическое осознание однородного звучания поэтического текста. Так как во французском языке отсутствует редуцирование гласных в неударной позиции, это создает основу его мелодичности. Природная четкость и энергичность произношения согласных позволяет ясно воспринимать текст сочинения. Благодаря символической активности (термин В. В. Левицкого) французских фонем (носовых, увулярных, лабиализованных) в поэтическом тексте заложена определённая эмоциональная тональность, а каждый звук вербального текста несёт важную семантическую нагрузку. Так, например, часто встречающиеся фонемы «е́», «i», «1», сочетание гласных «е́» или «ѐ» с носовыми в первом монологе «Rencontre» придают произведению мягкий и светлый тон, а наличие во втором «Toujours» таких звуков и комбинации звуков, как «s - fui» 
создают ощущение учащённого дыхания, волнения. Часто встречающиеся назальные фонемы вносят в поэтический текст Ш. Гранмужена особый шарм и мелодичность, что было созвучно эстетическим предпочтениям Г. Форе. Поэтому, создавая музыкальный текст «Поэмы одного дня», композитор подчёркивает достоинства стихосложения, постоянно соблюдая стихотворный размер Ш. Гранмужена, отделяя каждую новую строку более продолжительной длительностью.

Проведя лингвистический анализ французского первоисточника, можно констатировать, что характерные для французской речи постепенные подъёмы от начального до конечного слога внутри ритмической группы в музыке Г. Форе получают индивидуальное интонационное воплощение. В мелодической линии фореевских миниатюр переход от высокого звука предшествующей ритмической группы к более низкому безударному слогу последующей группы осуществляется плавно, о чём свидетельствуют часто встречающиеся лиги в музыкальном тексте. Восклицательные предложения, отражающие экспрессию главного героя, характеризуются эмфатическим ударением, по тону превышающим логическое. Чувственные метафоры, которыми изобилует первоисточник, органичны лирическому и эмоциональному содержанию вокальной партии.

Благодаря музыке Г. Форе в звуковое пространство миниатюрных поэтических текстов проникает тонкая одухотворённость, трогательная нежность, лёгкая меланхолия, глубокий драматизм, душевное успокоение. Целую гамму внутренних ощущений, заложенных в «Поэме одного дня», интерпретатор должен передать, сохраняя языковую культуру, изысканный вкус, обострённое понимание авторского замысла.

В представлении французской исследовательницы Мари-Клэр Бельтрандо-Патье для вокальных сочинений в жанре mélodie необходимы особые исполнители и особые слушатели. Понятие «особый исполнитель» предполагает вокалиста с достаточным багажом знаний французского языка, способного понять художественную целостность музыкально-поэтической конструкции вокальных сочинений французского композитора и умеющего затем изысканно воплотить тайный смысл, закодированный в поэтическом и музыкальном текстах в исполнительской интерпретации. Понятие «особый слушатель» включает элитарного слушателя, того, кто может понять и оценить интеллект и вкус создателей сочинения (композитора, поэта, исполнителей). 
Выводы. Шарм вокальной музыки Г. Форе заключается в соответствии музыкальных интонаций тончайшим нюансам фонетического строя поэтического языка. Композитор является изящным интерпретатором французской лирической поэзии, отвечающей его вкусам. Вокалисты, включающие в свой репертуар «Поэму одного дня» и исполняющие это произведение на языке перевода, лишают слушателя музыки поэтического текста, в результате чего теряется шарм фореевского искусства. Изучение французского языка - важнейшее звено в постижении тайны гения.

\section{СПИСОК ЛИТЕРАТУРЫ}

1. Левицкий В. Звукосимволизм в лингвистике и психолингвистике. Науч. доклады высшей школы. Филологические науки. М., 1975. № 4. С. 54-62.

2. Сигитов С. Габриель Форе: монография. М. : Советский композитор, 1982. $280 \mathrm{c}$.

3. Champagne M. J. S. G.. The French song cycle (1840-1924): with special emphasis on the works of Gabriel Fauré. University of North Carolina at Chapel Hill, 1994. 606 p.

4. Faure M., Vivès V. Histoire et poétique de la mélodie française. Paris : CNRS Editions, 2000. 396 p.

5. Gartside R. «Poème d'un jour» In Interpreting the Songs of Gabriel Fauré, Geneseo. NY: Leyerle Publications, 1996. 86-94.

6. Graham J. Stokes R.. «Grandmougin and Poème D’un Jour». Gabriel Fauré: The Songs and Their Poets. Farnham, England: Ashgate, 2009. 117-121.

7. Guide de la mélodie et du lied. Sous la direction de B. Francois-Sappey et Gilles Cantagrel. Paris: Librairie Arthème Fayard, 1994. $920 \mathrm{p}$

8. Histoire de la musique. La musique occidentale du Moyen Age a nos jours. Sous la direction de Marie-Claire Beltrando-Partier. Paris : Bordas, 1995. 639 p.

9. Jankelevitch V. Faure et I' inexprimable. Paris, 1974. 364 p.

10. Kimball C. Gabriél Fauré. In Song. A Guide to Art Song Style and Literature. Milwaukee, WI: Hal Leonard, 2006. 586 p.

11. Nectoux J.-M. Fauré. Paris : Seuil, 1972. 187 p.

12. Verlaine P. Euvres poétiques. Texte établi, avec chronologie, introduction, notes, choix de variantes et bibliographie par J. Robichez. P., Garnier, 1969. $807 \mathrm{p}$.

13. URL: http://scholarworks.bgsu.edu/cgi/viewcontent.cgi?article $=1197 \&$ con text $=$ honorsprojects

\section{REFERENCES}

1. Levitsky, V (1975). Sound-symbolism in linguistics and psycholinguistics. Scientific. reports of the higher school. Philological Sciences. M., № 4. P. 54-62 [in Russian]. 
2. Sigitov, S. (1982). Gabriel Faure: a monograph. M.: Soviet composer 280 p. [in Russian].

3. Champagne, M. J. S. G. (1994). The French song cycle (1840-1924): with special emphasis on the works of Gabriel Fauré. University of North Carolina at Chapel Hill [in English].

4. Faure M., Vivès, V (2000). Histoire et poétique de la mélodie française. Paris : CNRS Editions [in French].

5. Gartside, R (1996). «Poème d'un jour» In Interpreting the Songs of Gabriel Fauré, Geneseo. NY: Leyerle Publications, p. 86-94 [in English].

6. Graham J. Stokes R. (2009) «Grandmougin and Poème D'un Jour». In Gabriel Fauré: The Songs and Their Poets, Farnham, England: Ashgate, 2009. 117-121 [in English].

7. Guide de la mélodie et du lied (1994). Sous la direction de B. Francois-Sappey et Gilles Cantagrel. Paris: Librairie Arthème Fayard [in French].

8. Histoire de la musique (1995). La musique occidentale du Moyen Age a nos jours. sous la direction de Marie-Claire Beltrando-Partier. Paris : Bordas [in French].

9. Jankelevitch, V (1974). Faure et I' inexprimable. Paris [in French].

10. Kimball, C. (2006). Gabriél Fauré. In Song: A Guide to Art Song Style and Literature. Milwaukee, WI: Hal Leonard, 2006 [in English].

11. Nectoux, J. (1972) M. Fauré. Paris : Seuil [in French].

12. Verlaine, P. (1969) Euvres poétiques. Texte établi, avec chronologie, introduction, notes, choix de variantes et bibliographie par J. Robichez. P., Garnier [in French].

13. URL: http://scholarworks.bgsu.edu/cgi/viewcontent.cgi?article=1197\&context $=$ honorsprojects

Стаття надійшла до редакції 15.03.2017

УДК $78.03+782.1$

\author{
Лариса Миколаївна Лобода \\ кандидат мистецтвознавства, доцент кафедри \\ сольного співу Одеської національної \\ музичної академії імені А. В. Нежданової \\ loboda_l@i.ua
}

\title{
ОСОБЛИВОСТІ ВОКАЛЬНО-СЦЕНІЧНОГО ВТІЛЕННЯ ПЕРСОНАЖІВ ОПЕРНОГО ТВОРУ
}

Метою статті є виявлення театрально-сценічних принципів $і$ вокально-виконавських прийомів, що сприяють втіленню образних характеристик оперного персонажа. Методологічна основа статті полягає в історико-стильовому з особливою увагою до естетичного походження

С Лобода Л. М., 2017 